\title{
The Influence of Ionizing Radiation on Itraconazole in the Solid State
}

\author{
Katarzyna Dettlaff, ${ }^{1,4}$ Przemysław Talik, ${ }^{2}$ Grzegorz Spólnik, ${ }^{3}$ Witold Danikiewicz, ${ }^{3}$ and Magdalena Ogrodowczyk ${ }^{1}$
}

Received 3 March 2014; accepted 23 July 2014; published online 27 August 2014

\begin{abstract}
The aim of this study was to investigate the ionizing radiation effects, in the form of an electron beam, on itraconazole (ITR) in the solid phase. It was found that the ITR, under the influence of a standard $25 \mathrm{kGy}$ dose of radiation used for the sterilization of drug substances, decomposed at $0.4 \%$. Moreover, a gentle change of colour and a decrease in melting point does not exceed pharmacopoeial standards causing that ITR can be sterilized by radiation method. The use of high $400 \mathrm{kGy}$ radiation doses resulted in a $6.5 \%$ decomposition of the ITR and eight radiodegradation products were found. However, with the exception of differential scanning calorimetry (DSC), the X-ray diffraction, Fourier transform infrared spectroscopy (FT-IR) and ultraviolet-visible (UV-vis) methods showed no changes in the form and the morphology of the crystals. The structures of all those compounds were investigated. It was confirmed that the ITR decomposition takes place by dehalogenation (one of $\mathrm{Cl}$ atom elimination), the oxidation in isobutyl residue (beside the triazole ring) and C-O bond rupture.
\end{abstract}

KEY WORDS: antifungal azole; DSC; itraconazole; product radiolysis; radiation sterilization.

\section{INTRODUCTION}

Itraconazole (ITR) $((2 R, 4 S)-1-($ butan-2-yl)-4-\{4-[4-(4$\{[(2 R, 4 S)-2-(2,4-$ dichloro phenyl)-2-(1H-1,2,4-triazol-1ylmethyl)-1,3-dioxolan-4-yl]methoxy\}phenyl)piperazin-1-yl] phenyl\}-4,5-dihydro- $1 \mathrm{H}$-1,2,4-triazol-5-one) is a third-generation antifungal azole, a derivative of 1,2,4-triazole (Fig. 1). It is characterized by a broad spectrum of action and its activity was found against Trichophyton spp., Microsporum spp., Epidermophyton floccosum, Candida spp. (including Candida albicans, Candida glabrata, Candida krusei), Malassezia spp., Cryptococcus neoformans, Histoplasma spp., Paracoccidioides brasiliensis, Blastomyces dermatitidis, Sporothrix schenckii, Aspergillus spp., Fonsecaea spp., Cladosporium spp., Geotrichum spp., Pseudallescheria boydii and Penicillium marnefei (1-3). A usual dose between 100 and $400 \mathrm{mg}$ daily is recommended orally (capsule) and parenterally (injections, solutions for infusion) to patients (4).

All parenteral drugs must be sterile. The radiation sterilization, which is one of the accepted methods of the European Pharmacopeia 6.0 (5), is applied more and more often $(6,7)$.

Above all, it can be conducted at room or lower temperatures which allow for thermolabile drug sterilization.

\footnotetext{
${ }^{1}$ Department of Pharmaceutical Chemistry, Poznan University of Medical Sciences, Grunwaldzka 6, 60-780, Poznań, Poland.

${ }^{2}$ Department of Inorganic and Analytical Chemistry, Jagiellonian University, Collegium Medicum, Medyczna 9, 30-688, Kraków, Poland.

${ }^{3}$ Institute of Organic Chemistry, Polish Academy of Sciences, Kasprzaka 44/52, 01-224, Warszawa, Poland.

${ }^{4}$ To whom correspondence should be addressed. (e-mail: dettlaff@ ump.edu.pl )
}

However, the most important limitation is the fact that the degradation of the drug molecule is possible. The factors causing the greatest damage during the irradiation process are radicals formed in the radiolysis reaction of water $\left(\mathrm{H}_{2} \mathrm{O}^{+}, \mathrm{OH}, \mathrm{H}_{3} \mathrm{O}^{+}, \mathrm{H}^{\prime}, \mathrm{O}^{\prime}, \mathrm{H}_{2}, e^{-}, e_{a q}{ }^{-}\right)(6,8)$. Therefore, the irradiation of therapeutic substances should be carried out in the solid state $(6,7,9)$. Although the first studies on the sterilization of drugs are dated back to the 70 s of the twentieth century (they concerned most often thermolabile antibiotics of the penicillin group), many of them has not known radiation resistance yet. It is estimated that about $90 \%$ could be sterilized in the solid phase; however, it should be proved for each drug that ionizing radiation does not change any of its physicochemical properties (6). The mechanism of radiodegradation is often different than the previously known mechanism either of photo- or thermodegradation. An assumption that the resistance of ionizing radiation is similar in the group of drugs with similar structure cannot be made (6,9-13). The comprehensive assessment for X-ray methods, spectroscopy, thermal and chromatographic analysis only enables capturing all changes that may occur during the irradiation process of a therapeutic compound, in order to ensure the safety of therapy $(6,9)$.

In the present paper, the effect of ionizing radiation as a beam of high energy electrons on the physicochemical properties of ITR in the solid phase has been investigated. A standard dose of radiation sterilization $(25 \mathrm{kGy})$ and higher radiation doses (50-400 kGy) have been applied to understand the mechanism of ITR degradation and also to compare the results of previous radiochemical stability studies, involving four other derivatives of azole antifungals: clotrimazole, fluconazole, ketoconazole and miconazole nitrate (10-13). 


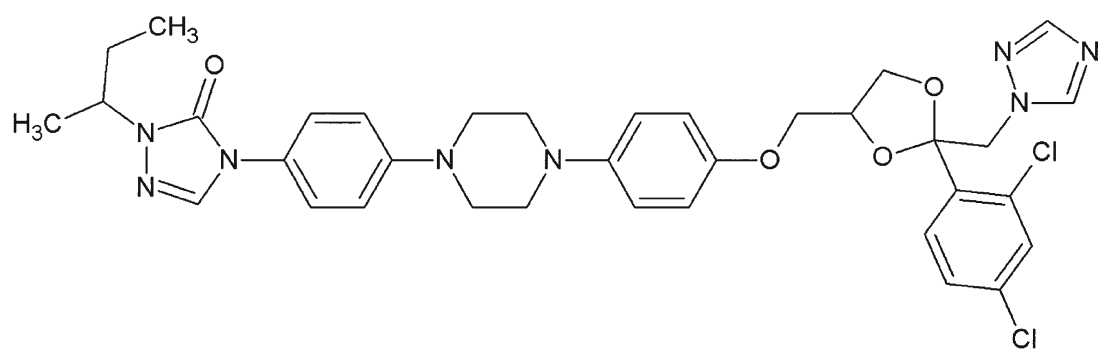

Fig. 1. Structure of itraconazole (ITR)

\section{MATERIALS AND METHODS}

\section{Materials}

The ITR pure white standard was purchased from Shouguang Fukang Pharmaceutical Co., Ltd, China, assay 98.5-101.5\% (in compliance with European Pharmacopeia 6.0-(5))-Fig. 1.

\section{Method of Exposure}

Approximately $0.2 \mathrm{~g}$ of ITR was placed in a colourless glass vial of 5-mL capacity, closed with a plastic stopper and exposed to an e-beam from a linear electron accelerator, Elektronika 10/ 10 (electron beam $9.96 \mathrm{MeV}$; current intensity $6.2 \mu \mathrm{A}$ ), until doses of 25, 50, 100, 200 and $400 \mathrm{kGy}$ were absorbed.

\section{Scanning Electron Microscopy}

The scanning electron microscopy (SEM) analysis was made using a SEM 515 (Philips, The Netherlands) electron microscope with $14 \mathrm{~mm}$ working distance and $3-10 \mathrm{kV}$ accelerating voltage. The ITR samples (about $2 \mathrm{mg}$ ) of 0 and $400 \mathrm{kGy}$ were placed on specimen stubs and fixed with carbon tabs; then, they were sputter-coated with gold in a sputter coater, type SCD 050 Balzers. Selected pictures were processed by Digital Image Scanning System (DISS).

\section{Fourier Transform Infrared Spectroscopy}

Two $\mathrm{KBr}$ discs were prepared by compressing the mixture of $1.00 \mathrm{mg}$ of ITR (before and after irradiation — $400 \mathrm{kGy}$ ) with $300 \mathrm{mg}$ of $\mathrm{KBr}$, in a Pye Unicam minipress. The spectra were recorded using the spectrometer IRAffinity-1 (Shimadzu, Japan) with $\mathrm{KBr}$ as a blank. The measurement parameters were as follows: range $500-4.000 \mathrm{~cm}^{-1}$, resolution $4.0 \mathrm{~cm}^{-1}$ and number of scans 40 .

\section{Ultraviolet-Visible Spectrophotometry}

The solutions were prepared by dissolving the ITR samples (from all irradiation doses $0-400 \mathrm{kGy}$ ) in methanol to a concentration of $0.02 \% \mathrm{w} / \mathrm{v}$. The solutions were examined using a Perkin Elmer UV/VIS Lambda 20 spectrophotometer (SpectraLab Scientific Inc., Ontario, Canada), in 1-cm cells in the range $200-800 \mathrm{~nm}$, using methanol as a blank.

\section{X-ray Diffractometry}

The X-ray diffraction patterns for ITR powdered samples (0, 25 and $400 \mathrm{kGy})$ were performed on a Bruker AXS D8 Advance powder diffractometer with a Johansson focusing monochromator $\mathrm{CuK} \alpha 1$ radiation $(\lambda=1.5406 \AA)$ at $25^{\circ} \mathrm{C}$ for the angles from the range $5^{\circ} \leq 2 \theta \leq 60^{\circ}$ (step size $0.05^{\circ} / 1.0 \mathrm{~s}$ ) and strip detector LynxEye, controlled by an IBM PC unit.

\section{Melting Point Determination}

The melting points of ITR were determined by capillary method using MP 70 Melting Point System (Mettler Toledo). The measurements were performed for unirradiated and irradiated ITR samples $(25,50,100,200$ and $400 \mathrm{kGy})$. Samples were heated from 25 to $175^{\circ} \mathrm{C}$, in the range $155-175^{\circ} \mathrm{C}$; heating rate was $1^{\circ} \mathrm{C} / \mathrm{min}$. The result was an average of three measurements.

\section{Differential Scanning Calorimetry}

The differential scanning calorimetry (DSC) measurements were performed in a nitrogen atmosphere with a flow rate of $50 \mathrm{~mL} / \mathrm{min}$ using an EXSTAR DSC 7020 apparatus (SII NanoTechnology Inc.) calibrated with indium and tin and equipped with DSC 7020 electric cooling unit. Samples of about 4.8 to $5.1 \mathrm{mg}$ were precisely weighted in aluminium pans and sealed. The samples were first equilibrated at $30^{\circ} \mathrm{C}$ for $15 \mathrm{~min}$, and thereafter, the melting behaviours were analyzed at a heating rate of $5^{\circ} \mathrm{C} / \mathrm{min}$. The measurements were performed at least three times and averaged.

\section{Ultra Performance Liquid Chromatography Coupled to High Resolution Mass Spectrometry}

Ultra performance liquid chromatography coupled to $>$ high resolution mass spectrometry (UPLC-HRMS) analysis was performed using the ultra-performance liquid chromatograph ACQUITY UPLC I-Class (Waters Inc.) coupled with a MALDISynapt G2-S HDMS (Waters Inc.) mass spectrometer equipped with an electrospray ion source and quadrupole-timeof-flight mass analyzer. UPLC separations was done with the $2.1 \times 100 \mathrm{~mm}$ ACQUITY UPLC BEH C18 $(1.7 \mu \mathrm{m})$ column (Waters Inc.). Solvent A was water and solvent B was acetonitrile. The gradient flow was used from the $30 \%$ of solvent $\mathrm{B}$ as the initial conditions to the $100 \%$ of solvent B at $13 \mathrm{~min}$, and it was maintained for $1 \mathrm{~min}$ and then back to initial conditions. The flow rate was $0.3 \mathrm{~mL} / \mathrm{min}$. The samples (ITR 0, 25 and $400 \mathrm{kGy}$ ) were diluted in acetonitrile. The peak at $2.40 \mathrm{~min}$ is present in all chromatograms and corresponds to the solvent background. 

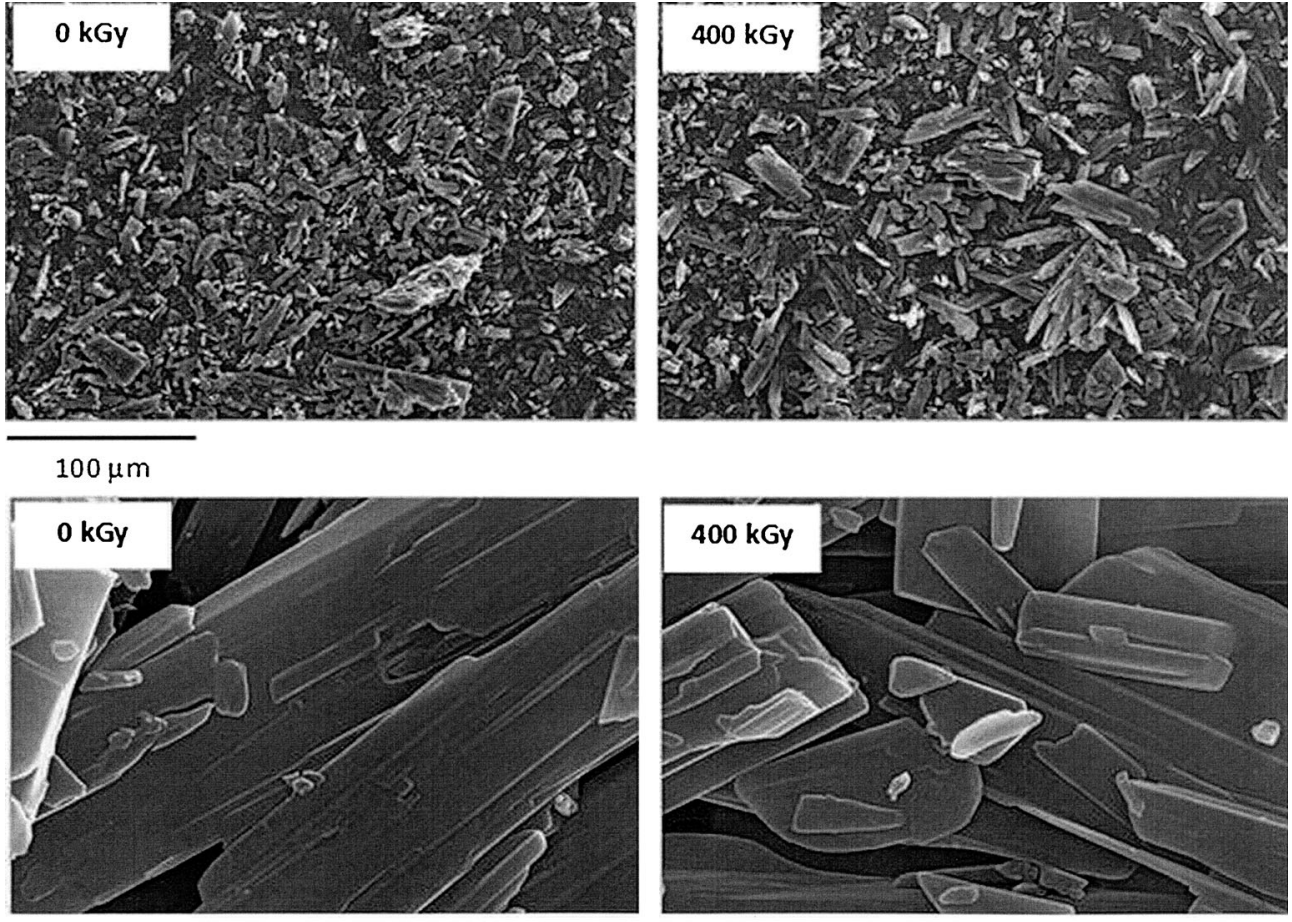

$5 \mu \mathrm{m}$

Fig. 2. SEM photographs of ITR before ( $0 \mathrm{kGy})$ and after irradiation $(400 \mathrm{kGy})$ in two magnifications

The measurements were performed in positive ion mode with the sampling cone set to $40 \mathrm{~V}$ and capillary voltage set to 3,000 V. The $\mathrm{MS}^{\mathrm{e}}$ experiments were set to collect the fragmentation spectra with the energy ramping from 30 to $50 \mathrm{eV}$.

\section{RESULTS AND DISCUSSION}

The first change of ITR colour from standard pure white to off-white and light grey was observed after irradiation with

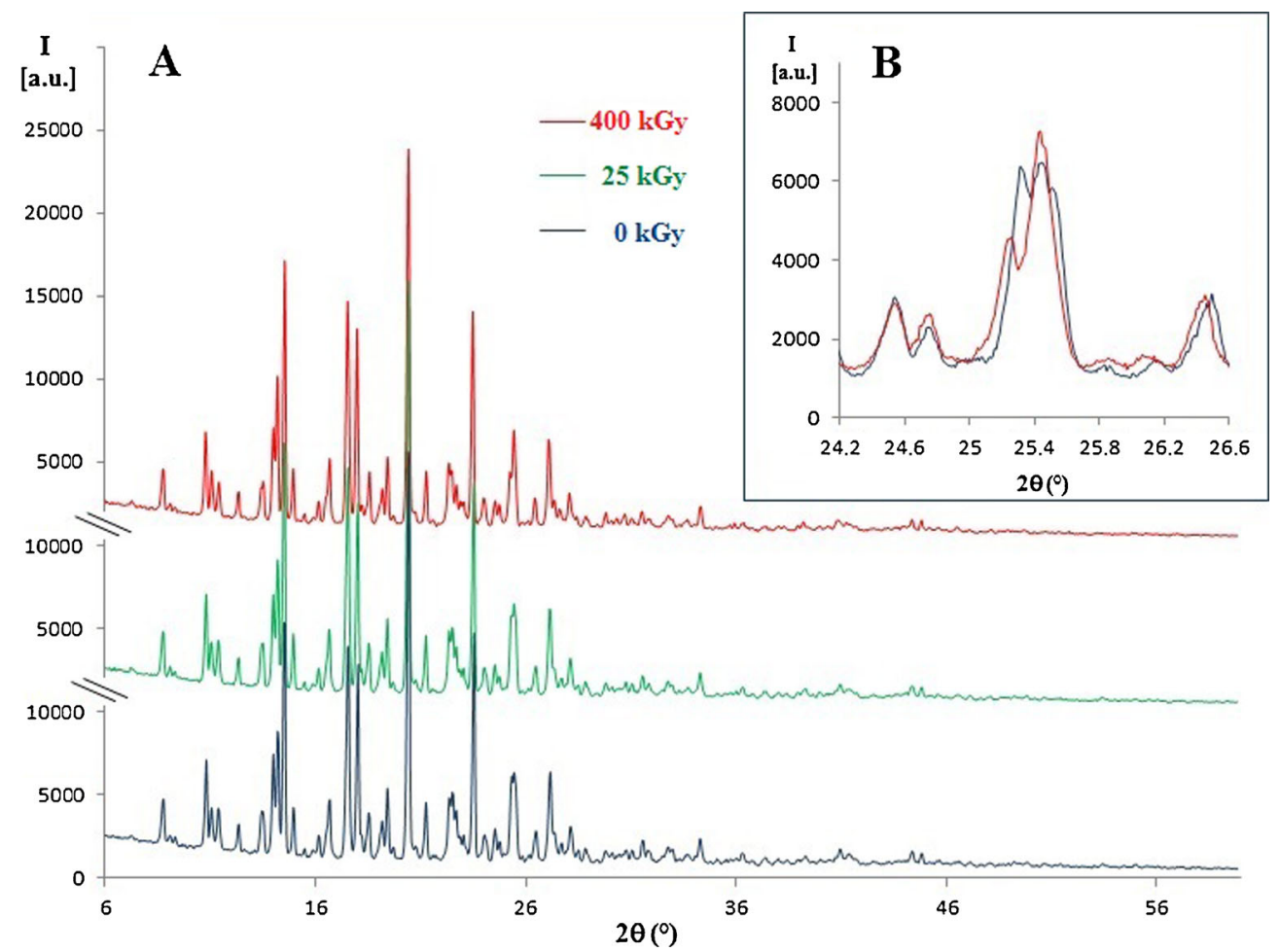

Fig. 3. a X-ray diffractograms of ITR before $(0 \mathrm{kGy})$ and after irradiation (doses 5 and $400 \mathrm{kGy}$ ), range $6.0-60.0^{\circ}$. b X-ray diffractograms of ITR before (0 kGy) and after irradiation (400 kGy), range 24.2-26.6 


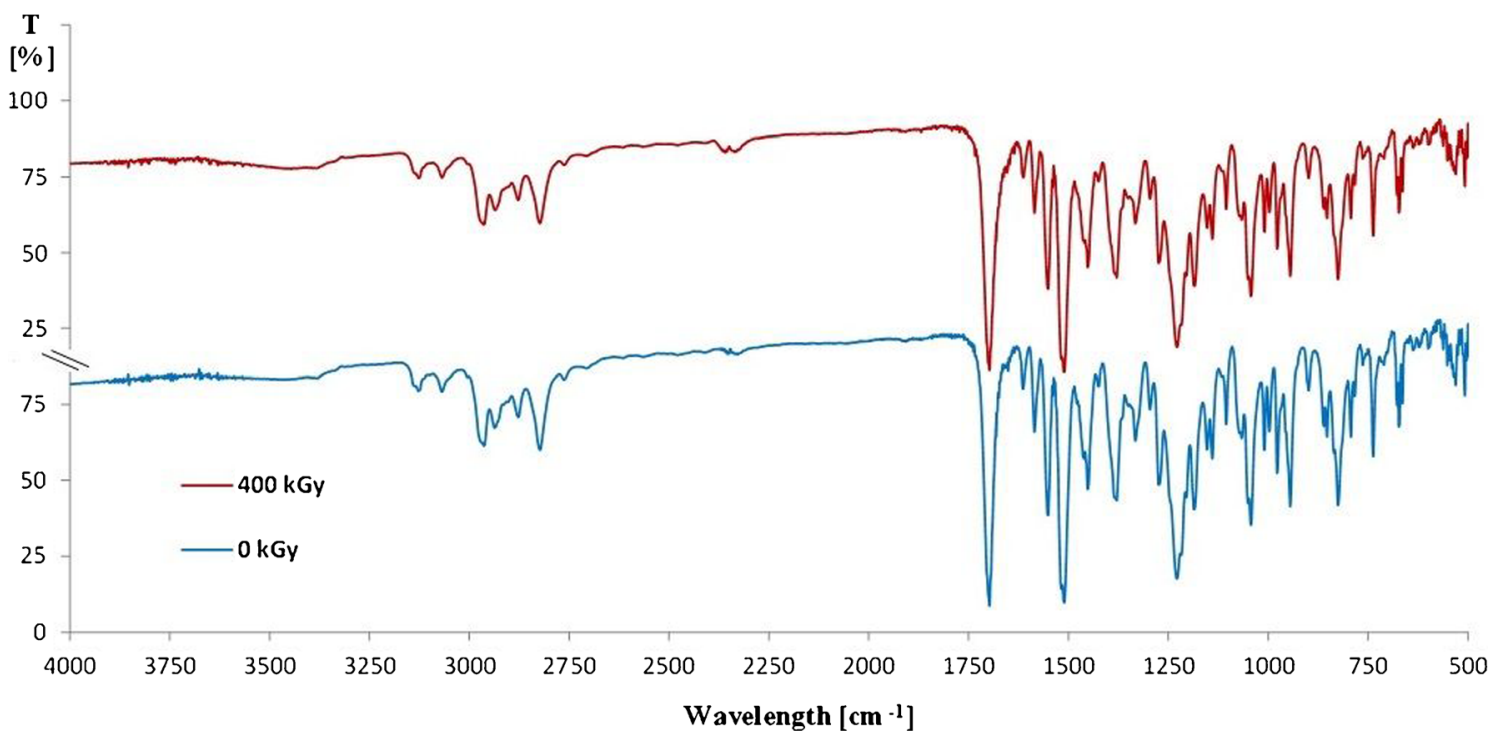

Fig. 4. FT-IR spectra of ITR before (0 kGy) and after irradiation (400 kGy)

dose of $50 \mathrm{kGy}$ and it was becoming more distinct and darker up to the grey-greenish colour ( $400 \mathrm{kGy}$ ) with the increase of radiation dose. To verify if there are changes in the dispersion degree or if there are a visible damages to the crystal morphology, the scanning electron microscope (SEM) was used. Our observations concerned two radiation doses 0 and $400 \mathrm{kGy}$. No such changes were observed (top images on Fig. 2) even in the larger magnification (bottom images).

\section{Spectroscopic Analysis}

To determine whether the colour of the compound is connected with the defects in the crystal lattice, the X-ray diffraction analysis of non-irradiated and irradiated (with doses of 25 and $400 \mathrm{kGy}$ ) ITR was performed. It was found that the location and intensity of the measured reflections were consistent (Fig. 3a). Only for sample exposed to dose
$400 \mathrm{kGy}$ slight changes in the range $25-26^{\circ}$ can be observed (Fig. 3b).

The next step was to analyze the spectroscopic studies. The Fourier transform infrared spectroscopy (FT-IR) spectra of ITR which were not subjected to ionizing radiation and which were irradiated with $400 \mathrm{kGy}$ (that was 16 times higher than a standard dose) are consistent throughout the entire course and transmittance values-Fig. 4.

So either there were no changes in the ITR structure or the radiodegradation products were formed in such a small content. That is, they can be either compounds with very similar structures to ITR or they are its structural isomers. Taking into account the large mass of the molecule (705 Da), a small impurity content which differs from the parent compound with more or less a single bond $(\mathrm{C}-\mathrm{H}$ or $\mathrm{C}-\mathrm{O})$ cannot be noticed in the mixture spectrum.

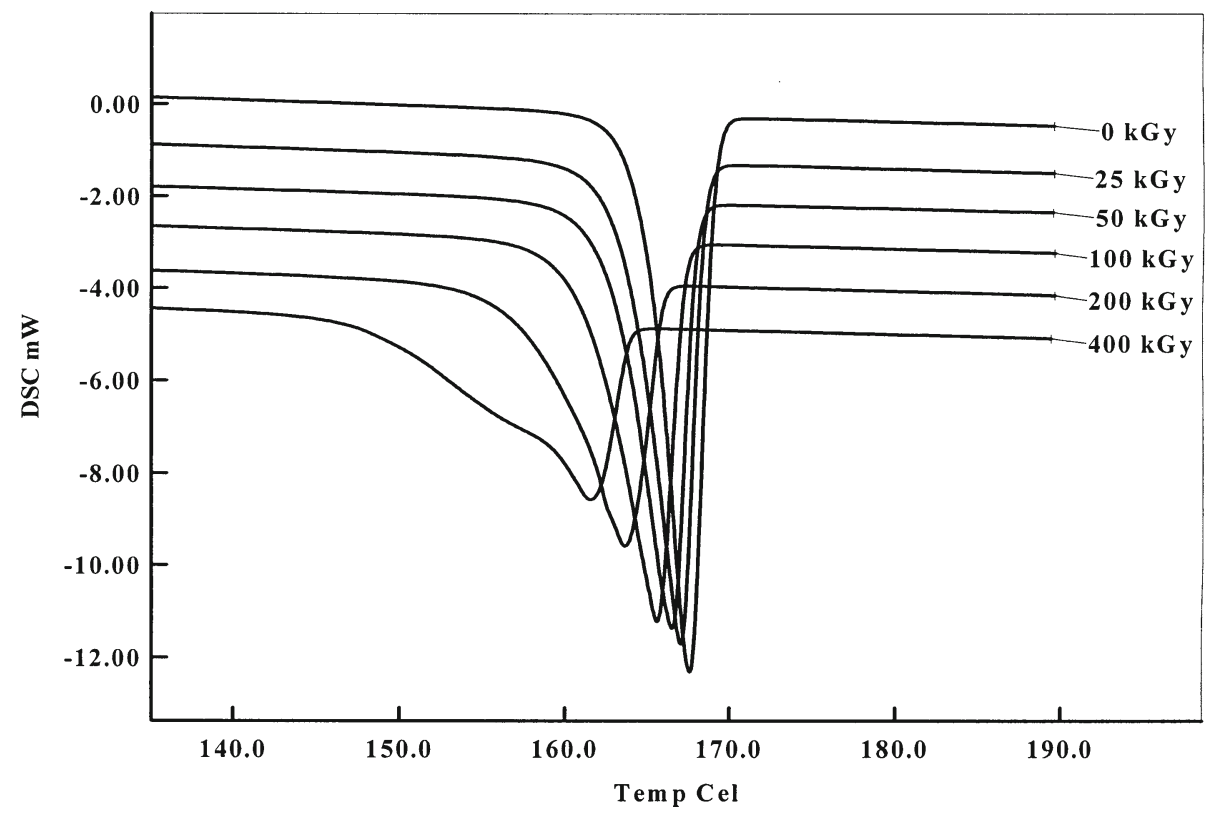

Fig. 5. DSC curves of ITR before and after irradiation 
Table I. Thermal Analysis Data Obtained by Means of DSC and Capillary Method; the Capillary Technique was Performed in Accordance with the Requirements of European Pharmacopeia 6.0 (5). All Values are Averaged at Least from Three Measurements; the Values in Parentheses are Standard Deviation (SD)

\begin{tabular}{|c|c|c|c|c|c|}
\hline \multirow[b]{2}{*}{ Dose (kGy) } & \multicolumn{3}{|c|}{ DSC } & \multicolumn{2}{|c|}{ Capillary method } \\
\hline & $T_{\text {onset }}\left({ }^{\circ} \mathrm{C}\right)$ & $\mathrm{T}_{\max }\left({ }^{\circ} \mathrm{C}\right)$ & $\Delta H\left(\mathrm{~J} \mathrm{~g}^{-1}\right)$ & $T_{\text {onset }}\left({ }^{\circ} \mathrm{C}\right)$ & $T_{\text {endset }}\left({ }^{\circ} \mathrm{C}\right)$ \\
\hline 0 & $164.8(0.40)$ & $167.6(0.00)$ & $-89.3(1.27)$ & $167.3(1)$ & $169.7(1)$ \\
\hline 25 & $163.5(0.08)$ & $167.1(0.06)$ & $-82.1(0.81)$ & $166.5(1)$ & $169.9(1)$ \\
\hline 50 & $162.7(0.31)$ & $166.4(0.13)$ & $-81.2(1.88)$ & $166.0(1)$ & $168.5(4)$ \\
\hline 100 & $161.1(0.10)$ & $165.5(0.13)$ & $-80.1(1.82)$ & $165.1(1)$ & $168.2(4)$ \\
\hline 200 & $158.7(0.50)$ & $164.0(0.23)$ & $-79.3(1.33)$ & $162.3(1)$ & $166.0(4)$ \\
\hline 400 & $155.7(0.53)$ & $161.6(0.10)$ & $-71.3(0.61)$ & $160.5(2)$ & $161.0(7)$ \\
\hline Difference $^{\mathrm{a}, \mathrm{b}}$ & $9.1^{\mathrm{a}}$ & $6.0^{\mathrm{a}}$ & $20.16^{\mathrm{b}}$ & $6.8^{\mathrm{a}}$ & $8.7^{\mathrm{a}}$ \\
\hline Norm (5) & - & - & - & 166.0 & 170.0 \\
\hline
\end{tabular}

${ }^{a} \Delta T_{\text {onset } / \text { max/endset }}=T_{\text {onset } / \text { max/endset }}{ }^{o k G y}-T_{\text {onset } / \text { max/endset }}{ }^{400 k G y}$

${ }^{b}\left(\Delta H_{0}-\Delta H_{400}\right) / \Delta H_{0}(\%)$

The spectrophotometric analysis of the ultraviolet and visible wavelengths allowed to conclude that the spectra of nonirradiated and irradiated ITR are consistent even at the highest dose. No new absorption band, as it was in the case of fluconazole (11) and clotrimazole (12), was observed. The absorbance decrease at the analytical wavelength for a $25-\mathrm{kGy}$ dose was $0.32 \%$ and for a $400-\mathrm{kGy}$ dose $1.08 \%$. It also indicates the compound stability or formation of radiolysis products which contain the same chromophore groups as the parent compound.

\section{Calorimetric Analysis}

Figure 5 shows the heating curves of ITR samples under study. The melting point represented by $T_{\text {onset }}$ and $T_{\max }$ shifts to the lower temperature side as the radiation level is increased, reaching values, for minimum $0 \mathrm{kGy}$ and maximum $400 \mathrm{kGy}$ dose, 164.8 and $167.6^{\circ} \mathrm{C}$ and 155.7 and $161.6^{\circ} \mathrm{C}$, respectively (Table I). It means that the sample composition has changed and consists of other compounds/impurities formed during the e-beam exposure. In consequence, the melting enthalpies $\Delta H$ decreased from $-89.3 \mathrm{~J} / \mathrm{g}(0 \mathrm{kGy})$ to $-71.3 \mathrm{~J} / \mathrm{g}(400 \mathrm{kGy})$. The presence of those radiodegradation products is also clearly visible in Fig. 6 where additional, overlapping peak, obtained from $400 \mathrm{kGy}$ sample, can be seen at $T_{\max }=$ $155.6^{\circ} \mathrm{C}$.

\section{Chromatographic Analysis}

Analysis of the collision-induced mass spectrometry (CID-MS) spectra recorded for the protonated ions of compounds $\mathrm{A}$ to $\mathrm{J}$ allowed to propose the structure of these compounds (Table II). It was found that the major radiodegradation products (compounds $\mathrm{G}$ and $\mathrm{F}$ ) are the ITR

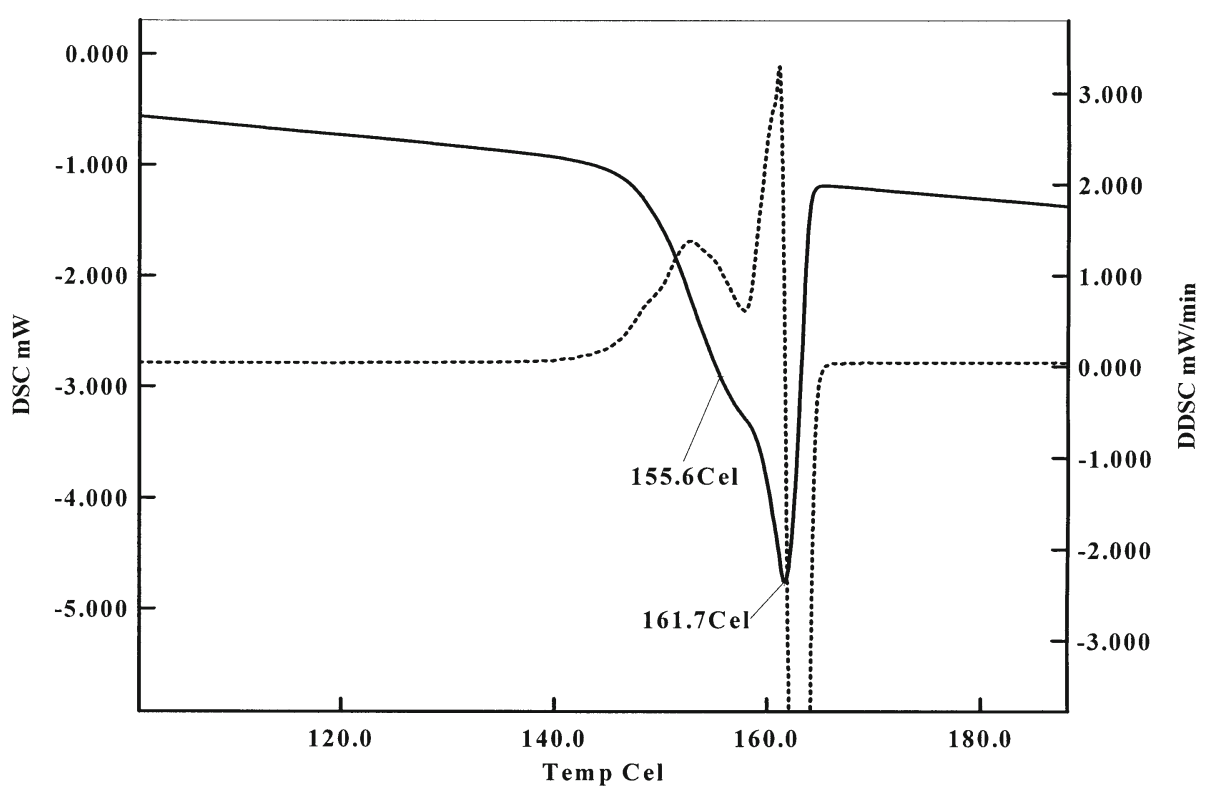

Fig. 6. DSC curve of ITR irradiated with $400 \mathrm{kGy}$ dose with additional peak at $155.6^{\circ} \mathrm{C}$ 
Table II. Proposed Impurities and Radiolysis Products of ITR

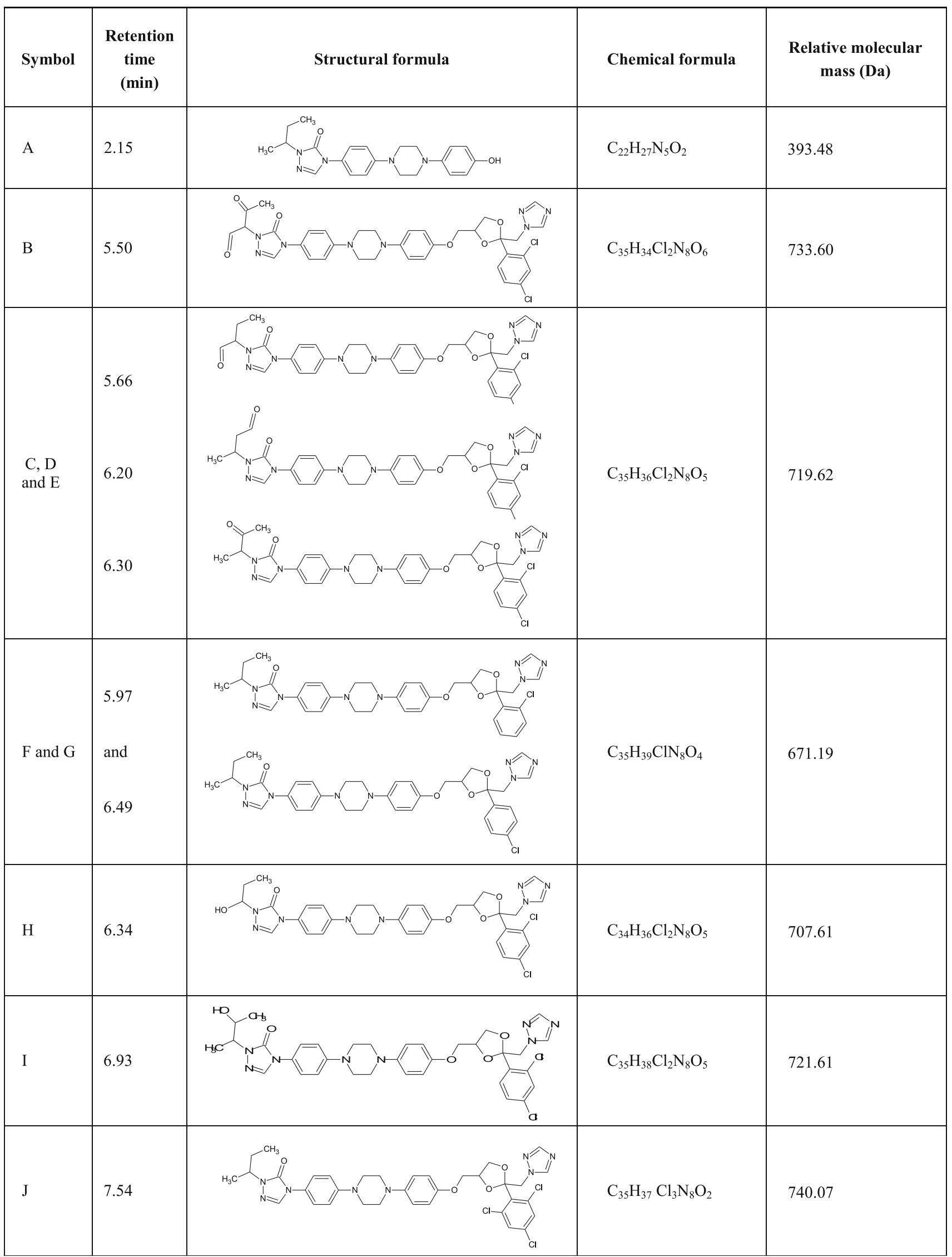




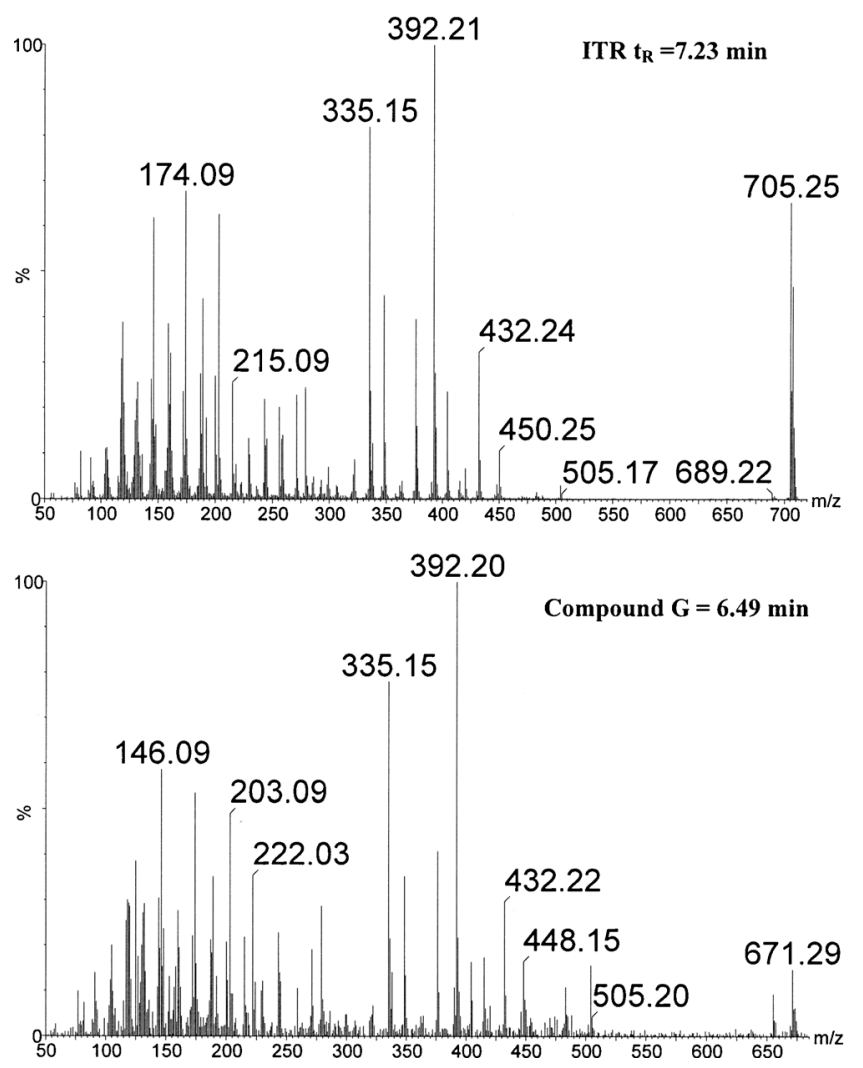

Fig. 7. CID-MS spectra of ITR and compound G (major radiodegradation product)

derivatives without one chlorine atom in the phenyl ring, one in the ortho and the second in the para position (Fig. 7). Other products are ITR derivatives resulting from the following reactions:

- Oxidation with dehydrogenation-compounds C, D and $\mathrm{E}$ (three isomers of the $\mathrm{C}=\mathrm{O}$ group position) and compound B.

- Oxidation with methyl group removal-compound H.

- Substitution of OH groups-compound I.

- C-O bond rupture reaction-compound A.

- Trace amounts of 2,4,5-trichlorophenyl derivative (compound $\mathrm{J}$ ) were also found in the ITR irradiated by a dose of $400 \mathrm{kGy}$ which may be a by-product of the formation of dechloroitraconazole.

Impurities found in the samples not exposed to irradiation are compounds formed by the oxidation mechanism. One can hypothesize that they are degradation products. Degradation proceeds very slowly at room temperature; however, under an atmosphere of air and ionizing radiation in the form of e-beam, it accelerates. Figure 8 shows the UPLC-MS chromatograms of nonirradiated (blue line) and irradiated with maximum $400 \mathrm{kGy}$ dose (red line) ITR samples. The analysis revealed low levels of compounds $H$ and $E$ in the nonirradiated ITR samples. They could be by-products of the compound synthesis or degradation products related to the sample ageing at room temperature. The irradiation decreased the content of the ITR about $0.4 \%$ after exposure to the dose of $25 \mathrm{kGy}$ and $6.5 \%$ after the dose of
$400 \mathrm{kGy}$. In addition to compounds $\mathrm{E}$ and $\mathrm{H}$, six radiodegradation products in the samples irradiated with a dose of $25 \mathrm{kGy}$ were found and their number increased to eight for the dose of $400 \mathrm{kGy}$ (Fig. 8, Table II).

The level of response of the mass detector for protonated ions of the studied compounds was used for the semiquantitative estimation of their content. Figure 9 shows the normalized recovery values. As it should be expected, these values increase with increasing doses of radiation. According to these data, compound $G$ is the main radiodegradation product and another one is

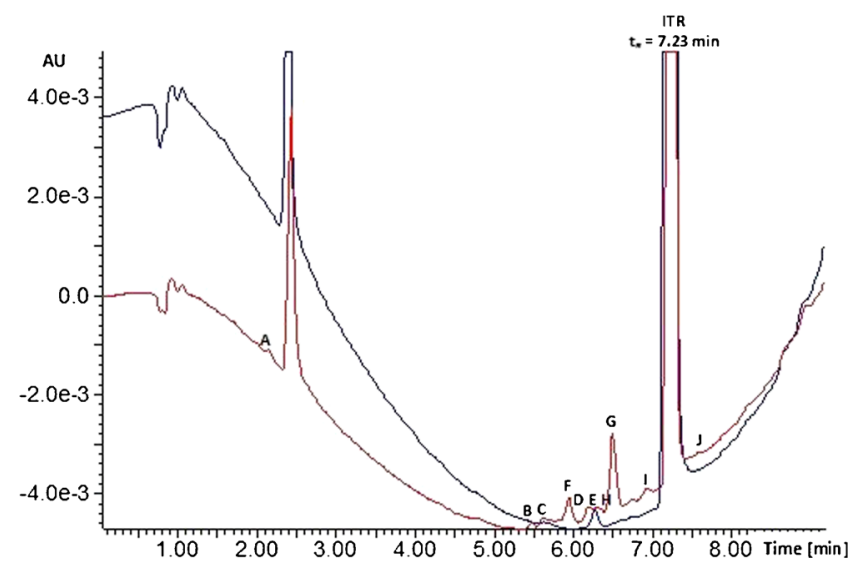

Fig. 8. UPLC chromatograms of ITR before (blue) and after irradiation with $400 \mathrm{kGy}$ dose (red) 


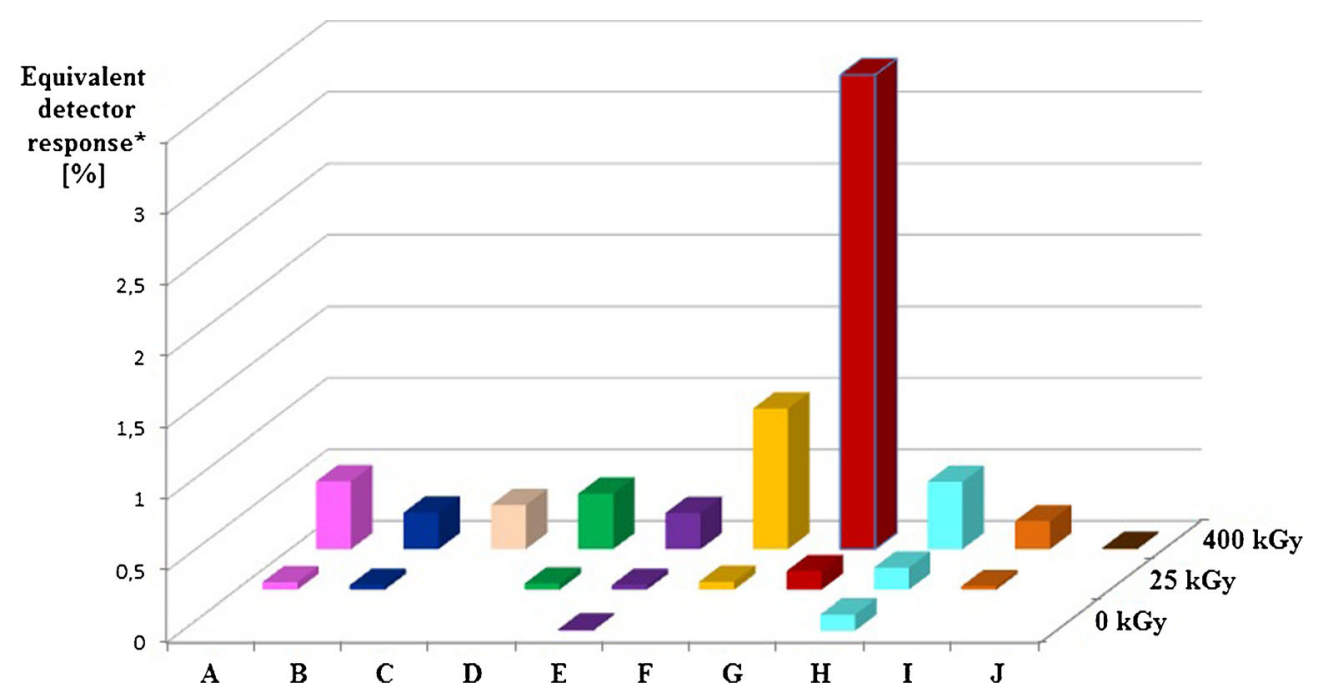

Fig. 9. The impurity profile of ITR before $(0 \mathrm{kGy})$ and after irradiation $(25$ and $400 \mathrm{kGy})$. Asterisk indicates $100 \%=$ sum of peak areas on chromatogram

compound F. It has to be noted that the contents of compounds $\mathrm{E}$ and $\mathrm{H}$ present in the non-irradiated ITR also increased after irradiation.

Main directions of radiodegradation pathway are shown in Fig. 10. It was found that monodehalogenation and oxidation reactions or $\mathrm{C}-\mathrm{O}$ bonds rupture were also observed in the ketoconazole (KK) (13). These compounds have many similarities in their structures; however, they differ in the type of azole (imidazole in KK, triazoles in ITR) and the substitution of the piperazine groups (acetyl group in KK and substituent alkyltriazolone in ITR). The main radiodegradation product of $\mathrm{KK}$, similarly to ITR, was a dechloro derivative and the rupture of the $\mathrm{C}-\mathrm{O}$ bond occurred as well. Under the influence of ebeam in air atmosphere, ITR was oxidized within alkyltriazolone substituent while KK, without such a substituent, formed $\mathrm{N}$-oxide within the imidazole ring. A demethylation occurred in both cases; however, due to the differences in structures, it took place in different parts of the molecules.

\section{CONCLUSIONS}

ITR is a compound with high radiochemical stability. The standard dose $(25 \mathrm{kGy})$ of radiation sterilization does not alter its physical and chemical properties that meet (capillary method-Table I) the requirements of the European Pharmacopeia 6.0 (5). It can be sterilized by radiation.

The analysis of crystalline form (X-ray diffractometry (XRD) and SEM) and spectroscopic methods (FT-IR, ultraviolet-visible spectrophotometry (UV-VIS)) did not detect changes in the properties occurring after ITR irradiation. However, DSC method has proved to be a useful tool to assess the compound degradation; a shift of the melting peak towards the lower temperatures illustrates the decrease in the ITR content.

To our knowledge, this is the first study testing the influence of ionizing radiation on itraconazole. Ten ITR derivative structures were separated by UPLC and analyzed by the CID spectra. On this basis, the main reactions of ITR

oxidation (to hydroxyl, aldehyde or ketone group)

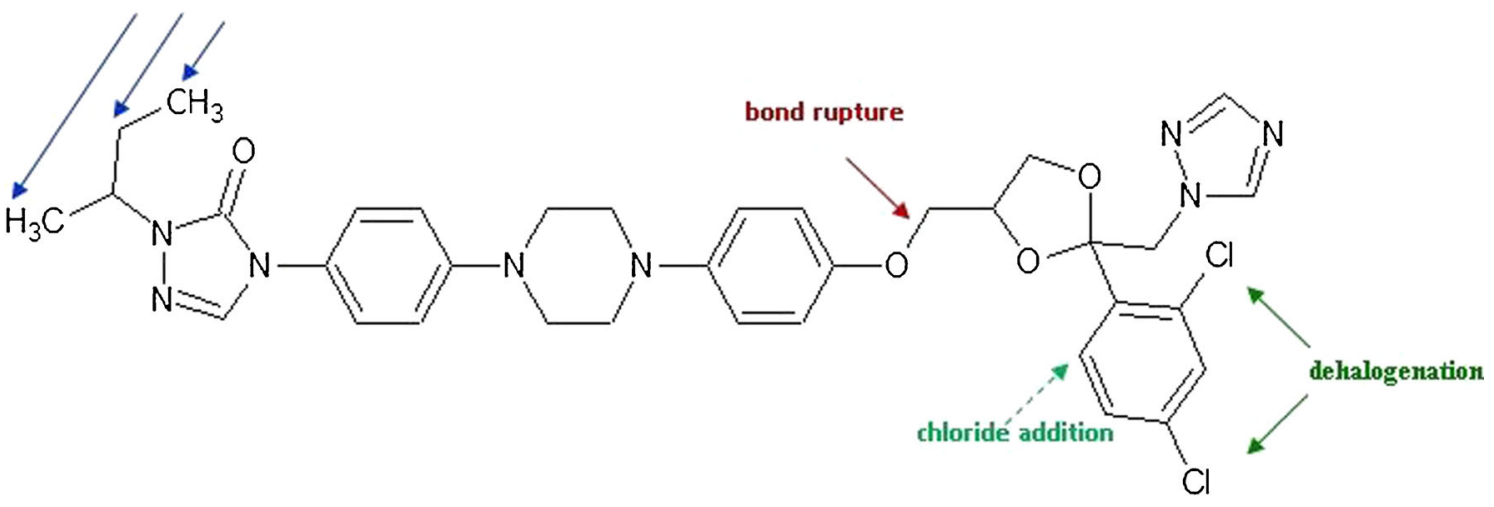

Fig. 10. Proposed radiolysis-induced processes pathway of ITR 
radiodegradation are as follows: dehalogenation $(\mathrm{Cl})$, more gradual oxidation and $\mathrm{C}-\mathrm{O}$ bond rupture.

Open Access This article is distributed under the terms of the Creative Commons Attribution License which permits any use, distribution, and reproduction in any medium, provided the original author(s) and the source are credited.

\section{REFERENCES}

1. Lass-Flörl C. Triazole antifungal agents in invasive fungal infections: a comparative review. Drugs. 2011;71:2405-19.

2. Maertens J, Boogaerts M. The place for itraconazole in treatment. J Antimicrob Chemoth. 2005;6 Suppl 1:i33-8.

3. Ekiert RJ, Krzek J, Talik P. Chromatographic and electrophoretic techniques used in the analysis of triazole antifungal agents-a review. Talanta. 2010;82:1090-100.

4. Moffat AC, Jacson JV, Moss MS, Widdop B. Clarke's analysis of drugs and poison: in pharmaceuticals, body fluids, and postmortem material. 4th ed. London: The Pharmaceutical Press; 2006.
5. European Pharmacopoeia. 8th ed. Strasburg: Council of Europe; 2010.

6. Marciniec B, Dettlaff K. Radiation sterilization of drugs. In: Trends in radiation sterilization of health care products. Vienna: IAEA; 2008. p. 187-230.

7. Silindir M, Ozer Y. The effect of radiation on a variety of pharmaceuticals and materials containing polymers. PDA J Pharm Sci Technol. 2012;66:184-99.

8. Mostafavi M, Douki T. Radiation chemistry: from basics to applications in material and life sciences ed. Spotheim-Maurizot M. EDP Sciences, 2008.

9. Bögl KW. Radiation sterilization of pharmaceuticals-chemical changes and consequences. Radiat Phys Chem. 1985;25:425-35.

10. Marciniec B, Kozak M, Dettlaff K. Thermal analysis in evaluation of the radiochemical stability of some fungicidal drugs. J Therm Anal Calorim. 2004;77:305-17.

11. Marciniec B, Dettlaff K, Jaroszkiewicz E, Bafeltowska J. Radiochemical stability of fluconazole in the solid state. J Pharm Biomed Anal. 2007;43:1876-80.

12. Marciniec B, Dettlaff K, Naskrent M. Influence of ionising irradiation on clotrimazole in the solid state. J Pharm Biomed Anal. 2009;50:675-8.

13. Marciniec B, Dettlaff K, Danikiewicz W, Spólnik G, Jaroszkiewicz E, Naskrent M. Radiostability of ketoconazole in the solid state. Curr Pharm Anal. 2013;9:102-13. 